\title{
As mulheres, os outros e as mulheres dos outros: feminismo, academia e Islão*
}

\author{
Maria Cardeira da Silva**
}

\begin{abstract}
Resumo
O véu, real ou metafórico, das mulheres muçulmanas faz, hoje em dia, parte de um claro e sonante argumentário político a diferentes níveis. Este artigo relembra a necessidade de objectivar o modo como as relações generificadas entre a Antropologia, o Islão e as políticas internacionais e nacionais contribuíram para a produção desse argumentário, concorrendo, assim, para o seu espessamento político. Para "descobrir" as mulheres muçulmanas, a Antropologia tem que se "desvelar" de constrangimentos políticos imediatos.
\end{abstract}

Palavras-chave: Feminismo, Feminismo Islâmico, Antropologia, Islão, Relações Internacionais, Direitos Humanos, Marrocos.

* Recebido para publicação em maio de 2008, aceito em junho de 2008.

** Departamento de Antropologia da Faculdade de Ciências Sociais e Humanas da Universidade Nova de Lisboa; CRIA - Centro em Rede de Investigação em Antropologia.smamc@fcsh.unl.pt

cadernos pagu (30), janeiro-junho de 2008:137-159. 
As mulheres, os outros e as mulheres dos outros

Womens and their Others

Feminism, Academy and Islam

\begin{abstract}
Nowadays, the veil of the Muslim women - either real or metaphoric - make part of clearly and sounding political rhetorics at different levels. It is my intention to remind that gendered relationships between Anthropology, Islam and international and national politics have largely supplied the production of this speech-making, concurring, thus, for its political thickness. This is why these relations must always stay under scrutiny regardless of the scale of our ethnographies, reminding us that the first step to 'unveil' Muslim women is to allow political immunity to anthropological inquiry.
\end{abstract}

Key Words: Feminism, Islamic Feminism, Anthropology, Islam, International Politics, Human Rights, Morocco. 
Os direitos das mulheres muçulmanas têm constituído, ao longo da história recente, uma importante fonte do argumentário político internacional, cuja eloquência se acentuou no Pós 11 de Setembro. Este argumentário tem sido esgrimido não apenas pelas sociedades ocidentais que relevaram a vitimação da mulher muçulmana para melhor afirmarem a sua superioridade moral $(e$, inclusivamente, reforçarem a justificação da sua intervenção militar de acordo com nos novos mapas de guerra), como por alguns países muçulmanos, os quais, com menor ou maior participação das suas mulheres, enfatizam a soberania nacional em termos civilizacionais através da radicalização da xari'a ${ }^{1}$ no que às mulheres diz respeito ou, ao contrário, acomodam os seus preceitos relativos às mulheres às directivas internacionais, pressionados pela necessidade de contrariar uma imagem que cada vez mais os associa ao terrorismo.

A politização dos direitos das mulheres ao nível das relações e da comunidade internacional não é, claro está, exclusivamente incidente sobre os contextos árabes e muçulmanos, nem tão pouco se trata de um fenómeno recente. A associação entre colonialismo e controle dos direitos das mulheres, bem como as complexas semelhanças entre um patriarcado mimético com o imperialismo e um feminismo que deveria ser etnoexcêntrico foram primeiro postos a claro pelos estudos subalternos (Spivack, 1985; Carby, 1982; Mohanty, 1984). Isso veio a estimular a generificação e racialização da história do colonialismo (Donaldson, 1993; McClintock, 1995; Mohanty, 2003).

Mas foi esse escrutínio generificado e comparado do colonialismo que cedo mostrou as especificidades da missão civilizadora consoante os contextos que subordinava: enquanto o avanço da civilização em África vestia as mulheres de algodão britânico branco e limpo, a penetração nos países árabes,

1 O uso exclusivo de termos de origem árabe suficientemente mediatizados e/ou incorporados no português não pareceu justificar regras de transcrição rígidas para este artigo. Recorre-se, por isso, a uma transcrição fonética simplificada. 
As mulheres, os outros e as mulheres dos outros

sobretudo no Magreb, despia/desvelava as mulheres muçulmanas (McClintock, 1995:31). Foi, factualmente, este desvelo que se exerceu em contexto colonial (Lazreg, 1994) ao mesmo tempo que, em casa, as mesmas mulheres veladas deleitavam o imaginário masculino ocidental, como sobejamente documentado (Rodinson, 1980; Alloula, 1981 e Mernissi, 1984, 1988).

$O$ véu que se hasteia como bandeira política e que, por vezes, não é mais do que a tradução económica, mas expressiva desta querela, voltou a arvorar-se e/ou a banir nas arenas mais recentes e domésticas dos contextos europeus multiculturais (França, Espanha, Holanda), de uma Turquia entalada entre a Europa e o Islão e, como vimos, dos novos roteiros de intervenção internacional, do qual o mais paradigmático terá sido o do Afeganistão. Na verdade, parece que assistimos a um estranho processo de globalização do véu como verbo da retórica política/cultural: um localismo globalizado (Santos, 1997) - nascido não num lugar cultural, mas em lugares específicos de confronto expresso culturalmente - que hoje se materializa em globalismos localizados (Id. ib.). Se já seria absurdo falar de uma mulher muçulmana, mais obtuso é, então, falar de um véu.

A difusão do uso político dos véus cedo se fez para além do lugar de confronto entre o Ocidente e o Islão. O mesmo desvelo, com igual clara intenção política, depressa se exerceu também em contexto de emergência dos nacionalismos. Em Marrocos, a imagem mais exibida disso foi a da Princesa Aicha - filha do futuro rei Mohammed V - a discursar sem véu em Tânger, no ano de 1943 (enquanto, de forma também politicamente eloquente, os homens se cobriam com os fez, os mesmos chapéus que Ataturk banira na Turquia). ${ }^{2}$

2 O Fez: também xexia ou tarbux; chapéu de feltro vermelho. É interessante reparar na negligência pelos estudos concomitantes das formas generificadas de cobrir e descobrir os homens e as mulheres em determinado contexto histórico e político nacional e internacional. Essa concomitância poderá ser uma das possíveis abordagens com vista ao desencapsulamento do debate reificado do véu. 
Apesar desta prolixidade, é leviano e melindroso dar demasiada importância a este acenar de véus sob o risco de reforçar a armadilha da auto-profecia huntingtoniana. Estacionar no debate relativo aos direitos das mulheres dos outros é ficar à beira do abismo inultrapassável das culturas essencializadas e do choque de civilizações. Mas, por outro lado, é impossível negar que ele se vem transformando em facto político que, como vimos, logo desde o período colonial passou a integrar a retórica interna dos novos países que, em muitos casos, importaram o idioma binário hegemónico. ${ }^{3}$

Entretanto, as epifanias do véu nas suas variantes foram-se refinando ao longo do último quarto do século XX na tensão entre o discurso feminista ocidental e outras tentativas emancipatórias regionais e/ou locais. Em sentido inverso, mas convergente com a generificação e racialização da história do colonialismo, o universalismo feminista ocidental viria a sucumbir à diversidade das agendas daquilo que polemicamente ficou designado como feminismo de Terceiro Mundo (Mohanty, Russo e Torres, 1991). E embora não tendo incidido especificamente sobre as mulheres e o harém (estranhamente, na medida em que esses seriam objectos perfeitos para levar as suas elucubrações ao extremo), o Orientalismo de Said (e, sobretudo, a sua popularização), quando justaposto com a reflexão pós-colonial e feminista, estimulou definitivamente novas abordagens aos mundos femininos islamizados (Cf. Abu-Lughod, 2001). Seria, no entanto, injusto omitir o processo de desmontagem que, antes disso, a academia encetara já com suas etnografias, num caminho que gostaria agora de acompanhar.

Ao partilhar o ocidental processo de desenvolvimento dos estudos antropológicos sobre as mulheres, os contextos e os

3 Não me posso referir aqui aos históricos movimentos prévios, nomeadamente o importante feminismo egípcio do final do século XIX e início do século XX e as manifestações magrebinas que os feminismos contemporâneos viriam a trazer à luz e ao presente. Para o caso magrebino, menos divulgado, veja-se Daoud, 1993. 
As mulheres, os outros e as mulheres dos outros

autores do Médio Oriente foram contaminados - para o bem e para o mal - pelas contingências da sua evolução.

Os women studies foram inicialmente espartilhados, de modo mais ou menos estruturalista, pela demanda de oposições universais homólogas: publico/doméstico, oficial/ oficioso, natureza/cultura (ex: Rosaldo e Lamphere, 1993). As abordagens em contexto islâmico recorreram frequentemente a esses pares inaugurais e o (então) grito feminista de que o "privado é político" serviu positivamente para iniciar o processo de desmontagem da imagem social passiva e culturalmente irrelevante da mulher no harém colonial (Alloula, 1981). Todavia, a mera revalorização do privado e do doméstico continuou, afinal, a acantonar ainda a mulher perpetuando a sua marginalização num espaço estrito e estandardizado, essencialmente determinado pelo discurso $e$ acção masculina e encontra-se mais ou menos dissimulado num vasto leque da literatura feminista dos anos setenta (Cf. Nelson, 1974).

Desde as primeiras antologias de textos sobre mulheres islâmicas, e como acontecia na literatura feminista ocidental, é enfatizada uma discrepância latente entre o nível dos valores institucionais e o da prática real, nomeadamente ao nível da sexualidade (ex: Vieille, 1978). Esta preocupação é obviamente positiva, compensando mesmo os perigos de essencialismo colectionista inerentes às colectâneas de então. Convém, contudo, dizer que esta tendência, nas suas expressões mais excessivas, arrastou consigo o risco de novo processo de segregação apriorística do mundo feminino ao remetê-lo insistentemente para a marginalidade e subversão da ordem institucional o que provocou, em alguns casos, nova polémica, consequente sucesso comercial e um alimento contraproducente do imaginário erótico masculino tão bem analisado, mas paradoxalmente reforçado, noutras obras feministas como La Femme dans l'Inconscient 
Musulman (Ait Sabbah, 1986). ${ }^{4}$ Terá sido por essa altura que terão surgido as primeiras reacções de autoras árabes face aos riscos de uma sobresexualização dos estudos sobre género nos seus contextos de origem (Cf. Jansen, 1989). E foi também então que começaram a surgir obras justapondo ao género outras configurações identitárias... como as de antropóloga: na obra conjunta Arab Women in the Field (Altorki e El-Sohl, 1988) antropólogas-mulheres-árabes ensaiam o timbre próprio da sua voz múltipla.

Mas foi ainda daquelas leituras duplamente dicotómicas que nasceram, com algum sucesso, "teorias hidráulicas da sexualidade" 5 nos contextos islamizados, onde se entende basicamente que os impedimentos teóricos às relações heterossexuais implicam e justificam culturalmente a prática de outras formas de gratificação sexual, por um lado, e o recurso a desvios e estratégias de compensação elaboradas, por outro. ${ }^{6} \mathrm{~A}$ mais espectacular destas abordagens, e aquela com maior alcance epistemológico, é sem dúvida a teoria do "terceiro sexo" encarnada pelos xanit uma espécie de prostituto transexual de Oman (Wikan, 1977). Ao apresentar esta espécie de género flutuante, Wikan expõe, embora de forma ainda incipiente, a complexidade da relação entre género e sexo, desmistificando a simplicidade bipartida das primeiras abordagens feministas $e$ apontando para a necessidade de libertar o género da matriz

4 Poder-nos-íamos questionar se não terá sido este tipo de vertigem que levou Fatima Mernissi, uma das mais eminentes feministas marroquinas - depois de escrever obras contra-orientalistas para o grande público $(1984,1988)$ e outras valiosas obras académicas de teor feminista e emancipatório (1975, 1987, 1990, 1992) - a publicar, em 1997, Rêves de Femmes.Une enfance au harem, uma obra de ficção onde revisita nostalgicamente a Fez da sua juventude segundo os arquétipos que tão veemente repudiara nas suas obras académicas.

5 A expressão, crítica é de Eickelman (1998 [1989, 1981]).

6 Estas interpretações estão latentes nas obras de autores como Vieille, 1978, Guessous, 1989, Mernissi, 1983 [1975], Bouhdiba, 1982 [1975], Chebel, 1984, 1988 , entre muitos outros. 
As mulheres, os outros e as mulheres dos outros

"natural" de duas entradas para o recolocar na grelha mais ampla e contextualizada das categorias culturais, antecipando a discussão mais alargada dos anos oitenta (Caplan, 1987).

O recurso abusivo aos modelos dicotómicos feminino/ masculino, público/privado - de importação em kit moderno $e$ ocidental - foi também responsável pela negligência pelo trabalho feminino que, ao não ser remunerado, foi frequentemente desvalorizado, e pela exclusão das mulheres do universo de relacionamento extra-doméstico. Na verdade, embora o enfoque masculino fosse reforçado pelas próprias ideologias indígenas, não há dúvida de que esse enviezamento era determinado por concepções apriorísticas do domínio doméstico percebido, à partida, como uma unidade compacta $e$ isomórfica.

Apesar de tudo, o empenhamento etnográfico foi evidenciando realidades mais diversificadas e complexas e, sobretudo, mulheres mais activas. Isso ficou testemunhado, no que respeita ao Médio Oriente, com a publicação de duas obras colectivas centrais logo nos finais dos anos setenta: Middle Eastern Muslim Women (Fernea e Bezirgan, 1977) e Women in the Muslim World (Lois e Keddie, 1978). Dando voz mais sonante $e$ diversificada às mulheres, estes estudos vão derruindo os rígidos muros que separavam o público do privado, a teoria da prática e, de modo mais subtil, as teóricas dicotomias que opunham o tribal ao doméstico e o rural ao urbano (Peters, 1978; Davis, 1978, 1983; Mernissi, 1986; Ferchiou, 1985; Maher, 1974, 1978). O reconhecimento da instabilidade social de muitas mulheres no Médio Oriente, suspensas entre o seu grupo de origem e o do seu marido, obriga à conclusão correlativa de que isso as torna exímias tecedeiras de laços políticos mais vastos que ligam núcleos patrilineares separados (Nelson, 1974). As mulheres muçulmanas começavam, a pouco e pouco, a mostrar que, afinal, saíam de casa.

As aproximações interpretativas (as únicas que Said viria a ilibar do pecado orientalista) fizeram-se sentir particularmente em Marrocos. Hildred Geertz teve um papel importante e aqui cabe 
uma reflexão, não relativa ao colonialismo generificado, mas à Antropologia generificada. Hildred, na sua participação em Meaning and Order in Morocco (1979), faz uma aproximação às redes e configurações sociais em Sefrou (Marrocos), descentrandoas da ideia etnocêntrica de família e do atavismo dos laços de parentesco biológico. Com isso, ela estava, eventualmente, participando do projecto do seu (então) marido e alimentando a guerra contra os teóricos da segmentaridade. E foi também, eventualmente, por isso ( $e$, por outras razões que descrevo em 1999b e 2004), que ela acentuou a importância das redes informais de vizinhança, amizade, laços vários estabelecidos por casamentos sucessivos e todo um outro emaranhado social que parecia ganhar mais consistência dentro do conceito nativo de qaraba $^{7}$ relativizando assim a importância do agnatismo. Ora, nesse novo enfoque, as mulheres aparecem muito mais nítidas $e$ dinâmicas. As perguntas a colocar aqui são as que questionam se, a) a descoberta da importância da participação das mulheres na reprodução e manutenção das redes sociais se deveu, em parte, ao facto de ela ser mulher (o que num contexto tão generificado condiciona inevitavelmente o enfoque), ou b) se, ao contrário, ela se deteve na importância das mulheres e da informalidade para acompanhar a contestação dos esquemas estruturalistas da teoria do parentesco (na linha do que Bourdieu fizera para a Cabília em 1972) e da segmentaridade, ou mesmo c) se a sua descoberta $e$ exibição da importância feminina $e$ informal não foi (correlativamente) um alimento importante para a consolidação da aproximação interpretativa empenhada em derrubar os esquemas funcionalistas $e$ estruturalistas que silenciavam $e$ domesticavam as mulheres, imitando as ideologias indígenas. Seja qual for a resposta, a 'libertação' das mulheres pela academia, pode ter sido, também aqui, condicionada pela agenda generificada, mais ou menos sofisticada, da academia.

7 Cuja pertinência Eickelman já havia sublinhado em 1976. Ver também Silva, 1999a. 
As mulheres, os outros e as mulheres dos outros

É verdade que em árabe clássico existe apenas um termo zauj - para designar qualquer metade de um par por referência a outro. É assim que é designada/o indiferentemente a esposa ou o marido, numa relação expressamente homóloga à do sol com a lua, à dos dois sapatos que compõem um par, ou à do número par com o ímpar (Cuisiner \& Miquel, 1962:37): a delícia dos estruturalistas. A plenitude do termo encontra-se na ideia múltipla da complementaridade recíproca entre as duas metades e no par resultante dessa mesma complementaridade: melhor ainda para os estruturalistas. Mas a capacidade harmónica, ou melhor, a eficácia dessa complementaridade recíproca, não é emanente do conceito em si. Ela só pode ser explicada e avaliada pela acepção que cada um dos termos - homem e mulher - lhe atribui, e que não é, necessariamente, comum. Foi isso que, de maneiras diferentes e originais, também Lawrence Rosen e Daisy Dwyer demonstraram para Marrocos, libertando os indivíduos e concedendo-lhes o direito de regatearem as suas próprias categorias de matriz sexual. Rosen, também no universo de Sefrou e na senda de Geertz conclui - através da análise comparada das noções de nafs (paixão) e 'aqal (razão) - que, apesar da subordinação efectiva das mulheres aos homens, elas tendem a interpretar a situação socialmente enquanto os homens enfatizam razões naturais para essa hierarquia (Rosen, 1978, 1984). Dwyer por seu turno, ao analisar um corpus de trinta e cinco contos recolhidos na região de Taroudent (Marrocos) integrando outros materiais de contextos afins, e através de uma interpretação também geertziana, confronta diferentes noções de feminino, masculino e sexualidade e põe em evidência a flexibilidade, a construção pela interacção da personalidade e dos papéis sexuais (Dwyer, 1978:181-2).

Apesar de tudo, neste quadro interpretativo, as barreiras da intelegibilidade cultural deixavam de parecer tão intransponíveis. E, concomitantemente, etnografias do particular (Abu-Lughod 1991) em diferentes contextos muçulmanos, vão minando, pelo interior, a noção encarcerante de área cultural. Abu-Lughod 
(1986), com a sua fina etnografia das beduínas dos Awlad 'Ali (Egipto), põe em causa, de forma particularmente subtil, o lago mediterrânico e masculino construído em torno dos gatekeeping concepts da honra, vergonha e assimetria de género (Peristiany, 1988 [1965]; Pitt-Rivers, 1971; Davis, 1977; Boissevan, 1979; Gilmore, 1982 e 1987). Ao analisar uma forma particular de poesia feminina (ghinawa) ela descobre uma performance que exibe a participação activa das mulheres no sistema moral beduíno em que honra $e$ modéstia são, afinal, valores partilhados por ambos os géneros. Abu-Lughod alerta mais uma vez para a necessidade de entendimento do sistema social tendo em conta homens, mulheres e o seu relacionamento, demonstrando, ao mesmo tempo, como a gestão da vida pessoal e o sistema de dominação "doméstica" da família e da linhagem se intersectam com a política segmentar da vida tribal, ambas fazendo parte do político (Abu-Lughod, 1989:286). Em 1993, com Writing Women's Worlds ela levará mais longe ainda a necessidade de revelar as mulheres dos Awlad 'Ali nos seus próprios termos e emoções. ${ }^{8}$

Tudo isto ia no caminho do que Strathern $(1981,1988)$ diagnosticara: as representações simbólicas não devem ser analisadas independentemente do modo como as mulheres se adaptam, na prática, ao poder informal que realmente detêm e a abordagem do género não deve alhear-se daquela que aproxima, simultaneamente a concepção de pessoa.

Ainda na aurora daquilo que se viria a designar por de feminismo islâmico (e alheia ao que já se passava no Irão, mas não tinha ainda ecos globais no mundo árabe), Chahla Chafiq (1991) classifica o tipo de abordagem predominantemente centrado no "estatuto da mulher islâmica", de acordo com três categorias: 1) as que denunciam o Islão como uma doutrina misógina - típica da linguagem feminista e onde podemos

8 Inaugurando uma série de livros devotados a "dar a palavra" às mulheres árabes, nas quais podemos incluir, para o caso marroquino, a obra de Mernissi Le Maroc Racconté par ses Femmes, 1986. 
As mulheres, os outros e as mulheres dos outros

enquadrar autores como Ascha (1987) e Ait Sabbah (1986 [1982]); 2) as que consideram essa atitude misógina como resultante de interpretações "erradas" ou "confusas" do Islão - um discurso veiculado com especial destreza e eloquência por Bouhdiba (1982 [1975]); 3) as que se concentram fundamentalmente na idade de ouro do Islão, nos seus primórdios, à procura da sua essência, para explicar em termos degenerativos a actual situação degradante da mulher islâmica - entre outros podemos aqui apontar o caso de Fatima Mernissi (1987), Magali Morsy (1989) e, talvez, acrescentar a de Leila Ahmed (1992), com maior impacto académico. O problema destas abordagens pode residir no seu duplo culturalismo: expresso, por um lado, na ideia de que a tradição islâmica é o elemento permanente da personalidade de base árabe-muçulmana (Boudhiba, 1982 [1975]) o que o aproxima perigosamente das tão criticadas posturas a la Grunebaum (1989 [1955]) - e, por outro, no pressuposto da existência de uma mulher islâmica, logo, de uma cultura feminina islâmica. ${ }^{9}$

Mas estes primeiros exercícios feministas da contemporaneidade, de certo modo culturalistas, não se podem considerar, senão marginalmente, dentro do movimento daquilo que viria a autodesignar-se como feminismo islâmico. Esse é um

9 Por exemplo, em Le Harem Politique (1987), Mernissi defende que o ímpeto igualitário do Islão original permitiu à mulher emergir como sujeito, enquanto na jahillia (período pré-islâmico) ela tinha o "estatuto de objecto" (Mernissi 1987; 1992:241, $\mathrm{n}^{\circ}$ 16). Em tempo de vida do Profeta as mulheres foram admiradas $e$ politicamente respeitadas. Foi o despotismo dos califas - precisamente aquele em que alguns autores (cf. Eickelman e Piscatori 1996:46-47) reconhecem a separação entre a "religião" e o "estado" (din ua daula) no seio do Islão - que recuperou novamente para as mulheres o seu estatuto pré-islâmico de escravas. Mernissi arrisca-se ao equívoco de uma possível interpretação fundamentalista da sua obra pela utilização que faz do vocabulário religioso: conceitos como os de jahilia e de fitna (desordem política e/ou sexual) são suportes de alguns discursos escrituralistas que utilizam o paradigma da sociedade pré-islâmica (précivilizacional e caótica), projectando-a no Ocidente e nos seus modelos importados e desestabilizadores, para forjar, por oposição, um modelo civilizacional, de inspiração divina, para os muçulmanos. 
conceito que só aparece na academia e nos meios intelectuais nos anos noventa e é especialmente emanado do Irão, forjado numa realidade política e cultural particular em que as mulheres encontram no ijtihad $^{10}$ e na luta pelo acesso a cargos jurídicos a melhor via para lutar pela sua ideia de emancipação (Moghadam, 2002). Para entender este movimento há que enquadrá-lo dentro do quadro mais geral dos movimentos reformistas que apostam na democratização da interpretação da $x$ ' $^{\prime} i^{11}{ }^{11}$, uma das tendências despontadas com a massificação do ensino e dos media (Eickelman e Anderson, 1999), no quadro de um Islão público emergente (Eickelman e Salvatore, 2004, 2006).

Algumas feministas preocuparam-se com os efeitos das aproximações pós-modernas e pós-coloniais destes novos feminismos que arriscavam desviar as atenções das instituições $e$ forças políticas locais, podendo pactuar com o que poderiam ser os maiores opressores das mulheres (Moghissi, 1999). Este posicionamento alertava para o facto de os projectos reformistas poderem servir simultaneamente agendas neoliberais $e$ agendas neo-fundamentalistas. As acepções de feminismo islâmico começam então a ser discutidas e decompostas. Valentine Moghadam (2002) introduz a distinção útil entre feminismo muçulmano - mobilizado por mulheres muçulmanas - e feminismo islâmico - mobilizado por mulheres participantes em movimentos islâmicos. E, embora a distinção classificatória não tenha vingado, foi certamente por já estar consciente da importância dessa discriminação que Shirina Ebadi, activista dos Direitos Humanos galardoada com o prémio Nobel em 2003, dissera em entrevista em 1999, a respeito do feminismo islâmico:

Se por isso entendemos que uma mulher muçulmana pode também ser feminista e que feminismo e Islão não são

\footnotetext{
${ }^{10}$ Interpretação, inovação.

${ }^{11} \mathrm{E}$, para ser mais exaustivo, no quadro dos novos movimentos sociais que se exprimem culturalmente (ver Silva, 2006).
} 
As mulheres, os outros e as mulheres dos outros

incompatíveis, eu concordo. Mas se isso significa que o feminismo nas sociedades muçulmanas é algo peculiar $e$ totalmente diferente de outras sociedades e que, portanto, será sempre islâmico, então não aceito o conceito (apud Moghissi, 1999).

Do seu ponto de vista, perspectivar o feminismo islâmico como o único ou o "autêntico" caminho para a emancipação acaba por implicar uma perspectiva orientalista ou essencialista de um determinismo islâmico, apenas simétrica àquela que encontra no Islão a grande fonte de legitimação da subordinação da mulher. Mas apesar da sua postura cautelosa, e suspendendo para já, pragmaticamente, a discussão, é também no seio do Islão que Ebadi constrói a sua argumentação jurídica: contestando, por exemplo, as múltiplas discrepâncias entre situações jurídicas de "maioridade" e de "menoridade" legal da mulher e outras contradições internas da lei iraniana, ela insiste que sendo o Islão unitário e coerente só há que concluir que "os nossos problemas não procedem do Islão, mas de uma mentalidade machista $e$ patriarcal daqueles que redigem a lei". Ora, são posturas como esta que sustentam a plataforma de luta comum entre as feministas seculares e islamistas do Irão. Elas são também a rampa para a contestação no interior do domínio sagrado $e$ exclusivamente masculino do fiqh (direito canónico islâmico). Desse ponto de vista, tanto as etnografias implicadas da antropóloga Mir-Hosseini, expondo comparativamente o esquema patriarcal dos juízes e dos litigantes no Irão e em Marrocos (MirHosseini, 1991, 1993, 1994 e 1999) ${ }^{12}$ a negociar soluções para os casos de divórcio "aberrantes" relativamente à xari'a, quanto as pesquisas de Fátima Mernissi e Leila Ahmed procurando desvios patriarquizantes na História do Islão, poderão considerar-se exercícios militantes de feminismo islâmico.

${ }^{12}$ Também co-realizadora, com Kim Longinotto, do celebre documentário Divorce: the Iranian style. 
Numa acepção ainda mais lata, o entusiasmo espoletado pela possível existência de um feminismo islâmico, nalguns casos, passou a incluir outras práticas femininas emergentes assumidas enquanto tal, ou meros feminismos informais ou práticos revelados em contestações ou apropriações quotidianas do Islão. Entendo agora, à distância, que o livro que escrevi em 1999 e que chamei Um Islão Prático, como muitos outros que, entretanto, apareceram exaltando o modo como as mulheres viviam $e$ "sobreviviam" ao Islão, respirava esse entusiasmo. Passados alguns anos, senti a necessidade de rever algumas das minhas posições à luz cruzada dos desenvolvimentos académicos e da concomitante evolução dos acontecimentos na vida quotidiana da medina de Salé (em Marrocos) onde havia trabalhado entre 1992 e 1994 e que continuei a revisitar regularmente (Silva, 1998, 1999b e 2003). Ao longo do tempo deixei-me surpreender pelo modo como, de formas para mim então imprevisíveis, algumas mulheres foram, progressivamente, fazendo recurso ao véu, à modéstia e a outros marcadores islâmicos, para colocar-se perante uma ideia de modernidade que lhes parecia mais conveniente, sobretudo no que respeita os modelos de conjugalidade (Silva, 2003).

A década de noventa terá sido marcada por aquela aposta dominante - cujos limites Mahmood (2002) viria a denunciar - na ideia de agencia frequentemente confundida com um princípio de oposição, ou com a noção gramsciana de resistência $e$ acomodação, e a obra mais paradigmática disso terá sido o trabalho de MacLeod sobre os novos véus no Cairo: Accomodating Protest (1991). Descobriu-se, então, que, em muitos casos, o véu era usado como símbolo da afirmação de uma identidade de género: afirmação face aos homens muçulmanos mais do que face aos não muçulmanos, como etnocentricamente muitos pensam. O véu surgia assim também como uma forma de resistência dos dominados. Mostrou-se, assim, que são as mulheres, e não a religião, que devem estar no centro deste debate e que "in every group, in every place, at every time, the 
As mulheres, os outros e as mulheres dos outros

meaning of 'feminism' is worked out in the course of being and doing" (Suad, 1998). ${ }^{13}$

Mas hoje, novas etnografias localizadas do uso do véu e de posturas pietistas muçulmanas, vão ainda mais além. Em Politics of Piety in Egypt. The Islamical revival and the Feminist Subject, Saba Mahmood ${ }^{14}$, tomando o Islão como tradição discursiva (na pista de Foucault e de Talal Asad, mas também de Leila AbuLughod), analisa os movimentos femininos pietistas emergentes nas mesquitas do Cairo, cuja importância é negligenciada na paisagem política do Egipto. Sem visar, de forma nenhuma, camuflar formas de violência e dominação, masculina e outra, nos contextos em que se colocam nem, tão pouco, abafar movimentos seculares que lutam, com outras "tradições discursivas" pela libertação de homens e mulheres, Sabah Mahmood limita-se a perguntar "What do they aim at doing so? And why?" [O que é que eles/elas pretendem ao fazer isso? E porquê?] em vez de "Why are they not behaving as expected?" [Porque eles/elas não se comportam conforme esperado?], como Asad sugerira em 1996. Mantendo essa postura: ela mostra como algumas mulheres, aderindo a práticas e assembleias de discussão islâmica, estão apenas procurando caminhos e orientações para serem "melhores pessoas", através da incorporação dos itens culturais e também sociais, locais, num processo de autocultivação moral. O véu é aqui uma prática disciplinar que constitui subjectividades devotas. E para vislumbrarmos o seu sentido temos que ser capazes de o perspectivar para além do binómio resistência/subordinação.

$\mathrm{Na}$ Antropologia, o locus da observação do uso do véu passou da religião/cultura ao género (as mulheres), para se focalizar, finalmente, na ideia de pessoa. $O$ enfoque da aproximação passou da dominação à resistência, para se

13 "em todos os grupos, em todos os lugares, em qualquer momento, o significado de 'feminismo' é forjado concomitantemente com o que se é e o que se faz".

${ }^{14}$ Para uma versão resumida, mas eloquente, em português, ver Mahmood, 2006. 
concentrar, por fim, na construção subjectiva da ideia de pessoa $e$ agência que, entre muitas outras coisas (classe social, nação, percurso biográfico) é também determinada cultural/ religiosamente, e que não implica necessariamente luta, ou resistência, para alcance da liberdade nos moldes em que, eventualmente, alguns outros a concebem e ambicionariam.

Como diz ainda Mahmood,

by allowing theoretical inquiry some immunity from the requirements of strategic political action, we leave open the possibility that the task of thinking may proceed in directions not dictated by the logic and pace of immediate political events (Mahmood, 2005:196). ${ }^{15}$

O sucesso da revisão da Moudawana, discutido neste volume e o aparente consenso - ou concomitante congratulação de feministas "seculares" e de feministas "islamistas" em relação ao novo Código da Família aprovado pelo Parlamento marroquino em 2004 só poderá ser entendido antropologicamente se nos colocarmos nessa mesma postura. ${ }^{16}$

\section{Referências bibliográficas}

ABu-Lughod, Lilá. Veiled Sentiments. Honour and Poetry in a Bedouin Society. Berkeley/Los Angeles, University of California Press, 1986.

. Writing against Culture. In: Fox, Richard. (ed.) Recapturing

Anthropology: Working in the Present. Santa Fe, NM, School of American Research Press, 1991, pp.137-62.

. Writing Women's Worlds. Bedouin Stories. Berkeley/Los

Angeles, University of California Press, 1993.

\footnotetext{
15 "ao consentir ao questionamento teórico alguma imunidade em relação aos requisitos da ação política estratégica, abrimos a possibilidade de que a tarefa de pensar possa seguir direções não ditadas pela lógica e pelo alcance de eventos políticos imediatos".

${ }^{16}$ Para uma articulação específica nessa linha, veja-se Ramirez, 2006 e 2007.
} 
As mulheres, os outros e as mulheres dos outros

. Do Muslim Women Really Need Saving? American Anthropologist, 104 (3), 2002, pp.783-790.

. Orientalism and Middle-East Feminist Studies. Feminist Studies, vol. 27, n 1, 2001, pp.101-113.

AHMED, Leila. Women and Gender in Islam: Historical Roots of a Modern Debate. Yale University Press, 1992.

Ait SabBAH, Fatna. La Femme dans l'Inconscient Musulman. Désir et Pouvoir. Paris, Albin Michel (C) Paris/Le Sycomore, 1986 [1982].

AlloulA, M. Le Harem Colonial: Images d'un sous-érotisme. Geneve/ Paris, Editions Slatkine, 1981.

ALTORKI, Soraya e EL-SolH, Camillia Fawzi. (eds.) Arab Women in the Field. Studying Your Own Society. Syracuse-Nova Iorque, Syracuse University Press, 1988.

ASAD, Talal. Modern Power and the Reconfiguration of Religious Traditions. Standford Electronic Humanities Review, vol. 5 (1), 1996.

AschA, Ghassan. Du Statut Inférieur de la Femme en Islam. Paris, Harmattan, 1987.

BADRAN, M. Feminists, Islam, and Nation. Gender and the Making of Modern Egypt. Cairo, American University in Cairo Press, 1996.

BECKE, Lois e KEDDIE, Nikki. Women in the Muslim World. Cambridge/ Londres, Harvard University Press, 1978.

BoISSEVAN, J. Toward an Anthropology of the Mediterranean. Current Anthropology 20, 1979, pp.81-93.

BouHDiBA, Abdelwahab. La Sexualité en Islam. Paris, PUF/Quadriga, 1982 [1975].

BouRdieu, Pierre. Esquisse d'une Théorie de la Pratique Précedé de Trois. Etudes d'Ethnologie Kabyle. Genebra, Droz, 1972.

CAPLAN, Pat. The Cultural Construction of Sexuality. Londres, Routledge, 1987.

CARBY, H. White Women Listen! Black Feminism and the Boundaries of Sisterhood. In: The Empire Strikes Back: Race and Racism in 70s Britain. London, Hutchinson, 1982, pp.212-235.

CHEBEL, Malek. Le Corps dans La Tradition au Maghreb. Paris, PUF, 1984. 
Maria Cardeira da Silva

. L'Esprit de Sérail. Paris, Lieu Commum/Terre des Autres, 1988.

CUISINIER, J. et MiQUEL, A. La Terminologie Arabe de la Parenté. Analyse Sémantique et Analyse Componentielle. L'Homme II, n²2, 1962.

DAOUD, Zakya. Féminism et Politique au Maghreb. Casablanca, Eddif, 1993.

DAVIS, John. The People of the Mediterranean: An Essay in Comparative Social Anthropology. Londres, Routledge \& Kegan Paul, 1977.

DAVIS, Susan Schaefer. Working Women in a Moroccan Village. In: BECKE, Lois \& KEDDIE, Nikki. Women in the Muslim World. Cambridge/Londres, Harvard University Press, 1978.

. Patience and Power: Women's Lives in a Moroccan Village. Cambridge, Schenkman, 1983.

DonALDSON, L. Decolonizing Feminisms. Londres/Nova Iorque, Routledge, 1993.

DWYER, Daisy Hilse. Images and Self-Images. Male and Female in Morocco. Nova Iorque, Columbia University Press, 1978.

EICKELMAN, Dale. Moroccan Islam. Austin/Londres, University of Texas Press, 1976.

. The Middle East - An Anthropological Approach. New Jersey, Prentice Hall, 1998 [1989, 1981].

e ANDERSON, Jon. New Media in the Muslim World. The Emerging Public Sphere. Bloomington, Indiana University Press, 1999.

and Salvatore, A. (eds.) Public Islam and the Common Good. Leiden, Brill, 2004. 2006, pp.97-105.

FERCHIOU, Sophie. Les Femmes dans l'Agriculture Tunisienne. Aix-en Provence, Edisud/Cérès Productions, 1985.

FERNEA, Elizabeth e BEZIRGAN, Basima Q. (dir.) Middle Eastern Muslim Women Speak. Austin/Londres, University of Texas Press, 1977.

GeERTZ, Hildred. The Meaning of Family Ties. In: GeERTZ, Clifford; GEERTZ, Hildred; ROSEN. Lawrence. Meaning and Order in Moroccan 
As mulheres, os outros e as mulheres dos outros

Society - Three Essays in Cultural Analysis. Cambridge, Cambrige University Press, 1979.

GILMORE, D. Anthropology of the Mediterranean Area. Ann. Rev. Anthropol. 11, 1982, pp.175-205. . (ed.) Honor and Shame and the Unity of the Mediterranean. Washington D.C., Am. Anthropologic. Assoc., 1987.

Grunebaum, G.E. Von. L'Identité Culturelle de l'Islam. Paris/Londres, Gallimard/Routledge and Kegan Paul, 1989 [1955].

GuESSOUS, Soumaya Naamane. Au de la de tout Pudeur. Enquête sur la sexualité de la femme Marocaine. Casablanca, Eddif, 1989.

Huntington, Samuel P. The Clash of Civilizations?. Foreign Affairs, vol. 72-3, 1993.

JANSEN, W. Women without Men: Gender and Marginality in an Algerian Town. Leiden, E. J. Brill, 1987.

LAZREG, Marnia. The Eloquence of Silence, Algerian Women in Question. N. Iorque, Routledge, 1994.

MACLEOD, Arlene E. Accomodating Protest. Working Women, the New Veiling and Change in Cairo. N. Iorque, University of Columbia Press, 1991.

MAHMOOD, Saba. Teoria Feminista, Agência e Sujeito Liberatório: Algumas Reflexões sobre o Revivalismo Islâmico no Egipto. Etnográfica, vol. X, 1, 2006, pp.121-158.

MCCLINTOCK, Anne. Imperial Leather. Race, Gender and Sexuality in the Colonial Contest. N. Iorque/Londres, Routledge, 1995.

MERNISSI, Fátima. Sexe, Idéologie, Islam. Paris, Tierce (C) Schenkman Publishing Company, Inc., 1975. . L'Amour dans les Pays Musulmans. Casablanca, Éditions Maghrebines, 1984. . Le Maroc Racconté par ses Femmes. Rabat, S.M.E.R, 1986. . Le Harem Politique. Le Prophète et les Femmes. Paris, Albin Michel, 1987.

Chahrazad n'est pas marocaine, autrement elle serait salariée! Casablanca, Editions Le Fennec, 1988. 
. Sultanes Oubliées. Femmes Chefs d'État en Islam. Paris, Albin Michel, 1990.

. La Peur-Modernité: conflit Islam et démocratie. Paris, Albin Michel, 1992.

. Rêves de Femmes. Une enfance au harem. Casablanca, Editions Le Fennec, 1997.

MiR-HosseinI, Ziba. Contrast Between Law and Practice for the Moroccan Family: Patriarchy and Matrifocality. Moroccan Studies, vol. I, 1991.

. Marriage on Trial: A Study of Islamic Family Law, Iran and Morocco Compared. Londres/Nova Iorque, I.B. Tauris, 1993.

. Strategies of Selection: Differing Notions of Marriage in Iran and Morocco. In: El-SolH, Camillia F. and MABRO, Judy. (eds.) Muslim Women's Choices. Religious Belief and Social Reality. Nova Iorque, Berg Publishers, 1994.

. Islam and Gender: The Religious Debate in Contemporary Iran. Princeton, Princeton University Press, 1999.

MOGHADAM, Val. Islamic Feminism and its Discontents. Notes on a Debate. Signs, 7, n 4, 2002, pp.1135-1171.

MoGHISSI, Haideh. Feminism and Islamic Fundamentalism: the Limits of Postmodern Analysis. Londres/Nova Iorque, Zed Books, 1999.

MOHANTY, Chandra Talpade. Under Western Eyes: Feminist Scholarship and Colonial Discourse. Boundarie 2, 1984, pp.71-92.

Feminism without borders: decolonizing theory, practicing solidarity. Durham/London, Duke University Press, 2003.

; RUSSO, Ann; TORRES, Lourdes. Third World Women and the Politics of Feminism. Bloomington, Indiana University Press, 1991.

Morsy, Magali. Les Femmes du Prophète. Paris, Mercure de France, 1989.

Nelson, Cynthia. Public and Private Politics: Women in the Middle Eastern World. American Ethnologist 1, n 3, August 1974.

PeRISTIANY, J. G. Honra e Vergonha, Valores das Sociedades Mediterrânicas. Lisboa/Londres, Fundação Calouste Gulbenkian/ George Weidenfeld \& Nicholson, 1988 [1965]. 
As mulheres, os outros e as mulheres dos outros

Peters, Emrys. The Status of Women in Four Middle East Communities. In: BECKE, Lois \& KEDDIE, Nikki. Women in the Muslim World. Cambridge/Londres, Harvard University Press, 1978.

PitT-Rivers, J.A. The People of the Sierra. Chicago, University of Chicago Press, 1971.

RAMIREZ, Ángeles. Outros feminismos? Associações muçulmanas e participação feminina em Marrocos. Etnográfica, vol. 10, n 1, 2006, pp.107-119.

. Paradoxes et consensus: le longue processus de changement de la Moudawana au Maroc. L'Année du Maghreb, Aixen-Provence, Éditions du CNRS, 2007.

Rodinson, Maxime. La fascination de l'Islam. Paris, Maspero, 1980.

Rosaldo, M. Z. e LAMPHERE, L. (eds.) Women, Culture \& Society. Standford, Standford University Press, 1993 [1974].

Rosen, L. Social Identity and Points of Attachment: Approaches to Social Organization. In: GeErTZ, C., GeErTZ, H. e Rosen, L. Meaning and Order in Moroccan Society - Three Essays in Cultural Analysis. Cambridge, Cambrige University Press, 1979.

. Bargaining for Reality - The Construction of Social Relations in a Muslim Community. Chicago/Londres, Univ. of Chicago Press, 1984.

SAID, Edward. Orientalism. Nova Iorque, Vintage Books, 1978.

SANTOS, Boaventura de Sousa. Por uma Concepção Multicultural dos Direitos Humanos. Revista Crítica de Ciências Sociais, vol. 48, 1997, pp.11-32.

SILVA, Maria Cardeira da. O Islão Plástico: Transformações da Intimidade em Contexto Popular Marroquino. Etnográfica, I (1), 1998, pp.57-72.

. Um Islão Prático: o Quotidiano Feminino em Meio Urbano Popular Marroquino. Oeiras, Celta, 1999a.

. Etnografias de Alfândega: Exercícios simples com vista à desterritorialização do trabalho de campo. Ethnologia, n's 6-8, Trabalho de Campo, Revista do Departamento de Antropologia da FCSH-UNL, 1999 b.

. O hammam, alguns anos depois: revisitação etnográfica de um contexto marroquino. Etnográfica, vol VII, nº 1, 2003. 
De que género é a África do Norte?. Actas do Congresso Africa Camina. Estudos Ibéricos sobre África. Barcelona, www.africacatalunya.org/congres/pdfs/ cardeira.pdf. Pub.CD, 2004.

. Social Movements in Islamic Contexts: Anthropological Approaches. Etnográfica, vol. X, nº 1, 2006.

SPIVACK, G. Can the Subaltern Speak? Speculations on Widow and Sacrifice. Wedge (7) 8, 1985, pp.120-130.

STRATHERN, Marilyn. No Nature, no Culture: The Hagen Case. In: MACCORMACK, C. and StRATHERN, M. (eds.) Nature, Culture and Gender. Cambridge, Cambridge University Press, 1980.

The Gender of the Gift. Berkeley, University of California Press, 1988 [O Gênero da Dádiva. Problemas com as mulheres e problemas com a sociedade na Melanésia. Campinas-São Paulo, Editora da Unicamp, 2006, Tradução: André Villalobos].

SUAD, J. Comment on Majid's: The Politics of Feminism in Islam: Critique of Politics and the Politics of Critique. Signs, vol. 23 (2), 1998, pp.363-369.

VIEILLE, Paul. Iranian Women in Famille, Alliance and Sexual Politics. In: BECKE \& KEDDIE. (eds.) Women in the Muslim World. Cambridge/ Londres, Harvard University Press, 1978.

WIKAN, Unni. Man becomes Woman: Transsexualism in Oman, a key to Gender Roles. Man 12, n 2, 1977.

Young, Robert. Colonial Desire. Hybridity in Theory, Culture and Race. Londres/N.Iorque, Routledge, 1995. 